\title{
Synthesis and Magnetic Property of Poly[bis(4-methoxyphenyl)aminiumacetylene]s
}

\author{
Hidenori Murata, Daisuke MiyajIma, Ryosuke TAKADA, and Hiroyuki NishidE ${ }^{\dagger}$ \\ Department of Applied Chemistry, Waseda University, 3-4-1 Okubo, Shinjuku-ku, Tokyo 169-8555, Japan
}

(Received June 2, 2005; Accepted August 4, 2005; Published November 15, 2005)

\begin{abstract}
Poly[bis(4-methoxyphenyl)aminiumacetylene]s $\mathbf{1}^{+}$were designed and synthesized as a $\pi$-conjugated polymer bearing multiple aminium radicals. Bis(4-methoxyphenyl)aminoacetylene and 1-methyl-2-bis(4-methoxyphenyl)aminoacetylene were synthesized and polymerized with a metathesis catalyst to yield poly[bis(4-methoxyphenyl)aminoacetylene] 1a and poly[1-methyl-2-bis(4-methoxyphenyl)aminoacetylene] 1b, respectively. The oxidation of $\mathbf{1}$ with $\mathrm{SbCl}_{5}$ gave the corresponding aminium polyradicals $\mathbf{1}^{+}$. The introduction of a methyl group onto the polyacetylene backbone in $\mathbf{1 b}^{+}$significantly enhanced the chemical stability or life-time of the poly(aminium radical). The highspin ground state with an average $S$ (spin quantum number) $=4 / 2$ for $\mathbf{1 b}^{+}$was proven by magnetic susceptibility, magnetization, and ESR measurements. [DOI 10.1295/polymj.37.818]

KEY WORDS Polyacetylene / Aminium Cation Radical / $\pi$-Conjugated Polymer / Ferromagnetic Interaction / Metathesis Polymerization /
\end{abstract}

High-spin macromolecules have been extensively investigated as a possible candidate for organic magnetic materials. ${ }^{1}$ One of the approaches to ferromagnetically align the spins on the radical groups is to focus on a $\pi$-conjugated linear polymer bearing the pendant radical group in a non-Kekulé and nondisjoint fashion. ${ }^{2,3}$ Such linear polyradicals bearing pendant spin sources possess the following advantages. ${ }^{3 \mathrm{~d}}$ First, a strong spin-exchange interaction occurs through the $\pi$-conjugated backbone, and potentially even works over a long range. That is, the exchange interaction is not sensitive to the defects that are unavoidable for macromolecular polyradicals. In addition, the spins are expected to interact not only with their neighboring spins but also with more remote spins. Second, the precursors of these types of polyradicals can be synthesized via a one-pot polymerization, and they and the polyradicals themselves are soluble in common solvents; these characteristics are very favorable for obtaining well-defined samples to study. Third, various radical species can be introduced into a polyradical as the pendant group. Such feasibility would be indispensable for the future application of organic polyradicals as a material.

Polyacetylene is one of the favorable candidates as a $\pi$-conjugated backbone because of its high molecular weight and the small acetylenic repeating unit. Polyacetylenes with a high molecular weight and substituent group have been reported to be obtained via the polymerization of the corresponding substituted acetylenic monomer using a catalyst, such as tungsten(VI) chloride and a rhodium complex. ${ }^{4}$ The substituted polyacetylenes are soluble in common solvents, and their chemical structure and purity could be rigorously defined. Among the substituted polyacetylenes, poly(phenylacetylene)s have been investigated as a backbone structure of the polyradical for magnetic materials, because of ferromagnetic through-bond interactions between the pendant spins theoretically predicted using simple polyene models. ${ }^{1 \mathrm{a}, 3 \mathrm{a}}$

Based on this molecular design, polyacetylenes substituted with the phenoxyl, nitroxyl or galvinoxyl radical group have been synthesized ${ }^{5}$ and their magnetic properties have been investigated by our group. The spin concentrations of these polyradicals were 0.7 per the molar repeating monomer unit, which was high enough to cause an exchange interaction between unpaired electrons. However, all the magnetic measurements of these polyradicals showed paramagnetism or weak antiferromagnetism, while no predicted ferromagnetic interactions between the pendant spins have been observed. These experimental results were discussed from the viewpoint of planarity in the $\pi$-conjugated molecules. For example, force-field modeling of the polyacetylenic radical showed a highly distorted polyene backbone (dihedral angle $c a .75^{\circ}$ ) as well as a twisted backbone-pendant phenyl dihedral angle ca. $45^{\circ}{ }^{6}$ This non-planar structure was considered to cause a reduction in the conjugated nature of the electronic structure and to decrease the spin density distribution over the polyradical molecules, especially for the polyradicals bearing nitronyl nitroxide and galvinoxyl radical groups whose spin density was almost localized on the oxygen atom of the radical residence.

In this paper, an aryl aminium cation radical was chosen as the pendant spin source of the polyacety-

${ }^{\dagger}$ To whom correspondence should be addressed (Tel: +81-3-3200-2669, FAX: +81-3-3209-5522, E-mail: nishide@waseda.jp). 


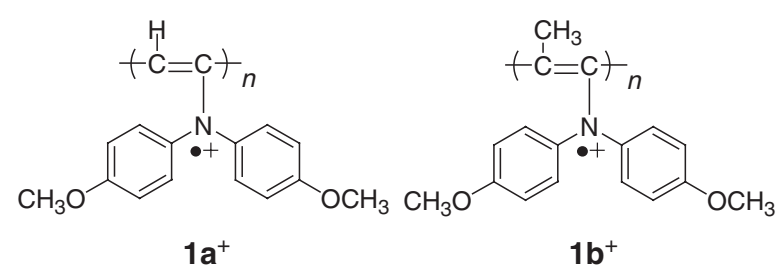

Chart 1.

lenic polyradical to realize a ferromagnetic interaction between the spins. It has been reported that the spin density of the aryl aminium radicals delocalizes into the three attached aryl groups, which efficiently works during the spin-exchange interactions. ${ }^{7}$ In addition, the triarylaminium cation radicals derived from the para-substituted triphenylamines are chemically stable and have been studied even as an oxidizing organic reagent and a catalyst in redox reactions. ${ }^{8}$ From such viewpoints, a series of oligomeric and polymeric aminium radicals were derived from $m$-phenylene-connected and cross-linked polyarylamines, and their magnetic behaviors have been reported. ${ }^{9}$ However, the aminium cation radicals were formed in a cross-conjugation style within the backbone for these molecules, which did not belong to the type of linear polymer bearing pendant radicals and which often lacked solvent solubility or quantitative radical generation. On the other hand, poly(1,2phenylenevinylene)-based poly(aminium cation radical)s with well-defined chemical structures have been synthesized and a ferromagnetic interaction through the $\pi$-conjugated poly(1,2-phenylenevinylene) backbone has been described. ${ }^{10}$ In this study, we designed and synthesized, for the first time, the combination of a pendant aryl aminium radical and a polyacetylene backbone, poly[bis(4-methoxyphenyl)aminoacetylene] $\mathbf{1 a}^{+}$and poly[1-methyl-2-bis(4-methoxyphenyl)aminoacetylene] $\mathbf{1} \mathbf{b}^{+}$, and succeeded in the highspin alignment with the spin quantum number of $S=$ $4 / 2$ in the polyradicals.

\section{EXPERIMENTAL}

\section{1-Bromo-2-triisopropylsilylacetylene}

To a solution of triisopropylsilylacetylene $(631 \mathrm{mg}$, $3.79 \mathrm{mmol}$ ) and $\mathrm{N}$-bromosuccinimide $(742 \mathrm{mg}, 4.17$ mmol) in $23 \mathrm{~mL}$ of acetone was added $\mathrm{AgNO}_{3}$ (3.4 $\mathrm{mg}, 20.1 \mu \mathrm{mol})$. The solution was stirred at $20^{\circ} \mathrm{C}$ for $2 \mathrm{~h}$, poured into ice/water/hexane, and washed with saturated $\mathrm{NaCl}$. The organic layer was evaporated to give the crude product, which was purified using a silica gel column with hexane to afford $971 \mathrm{mg}$ of 1bromo-2-triisopropylsilylacetylene as a colorless oil: yield $98 \% .{ }^{1} \mathrm{H}$ NMR $\left(500 \mathrm{MHz}, \mathrm{CDCl}_{3} ; \mathrm{ppm}\right) \delta 1.07$ $(\mathrm{s}, 21 \mathrm{H}) ;{ }^{13} \mathrm{C} \mathrm{NMR}\left(\mathrm{CDCl}_{3} ; \mathrm{ppm}\right) \delta 83.5,61.7,18.5$,
17.7. IR $\left(\mathrm{NaCl}, \mathrm{cm}^{-1}\right) 2132\left(v_{\mathrm{C} \equiv \mathrm{C}}\right) ; \mathrm{MS}(\mathrm{EI}) \mathrm{m} / e$ 260, 262, calcd for $\mathrm{C}_{11} \mathrm{H}_{21} \mathrm{BrSi}$ 261.3. Anal. calcd for $\mathrm{C}_{11} \mathrm{H}_{21} \mathrm{BrSi}$ : C, 50.6; H, 8.1; Br, 30.6; Found: C, $50.0 ; \mathrm{H}, 8.0 ; \mathrm{Br}, 30.8$.

\section{1-Bis(4-methoxyphenyl)amino-2-triisopropylsilylacety- lene 2}

1-Bromo-2-triisopropylsilylacetylene (137 mg, $0.523 \mathrm{mmol})$ and bis(4-methoxyphenyl)amine (120 $\mathrm{mg}, 0.523 \mathrm{mmol})$ were dissolved in toluene $(2.1 \mathrm{~mL})$. $\mathrm{Cs}_{2} \mathrm{CO}_{3}$ (340 mg, $1.05 \mathrm{mmol}$ ), bis(2-diphenylphosphinophenyl)ether $(44.2 \mathrm{mg}, 78.5 \mu \mathrm{mol})$, and palladium(II) acetate $(11.9 \mathrm{mg}, 52.3 \mu \mathrm{mol})$ were added, and then the mixture was heated at $100^{\circ} \mathrm{C}$ for $18 \mathrm{~h}$. The reaction mixture was neutralized with $1 \mathrm{~N}$ aqueous ammonia, and extracted with chloroform. The organic layer was washed with brine, and evaporated to give the crude product, which was purified using HPLC to afford $87.8 \mathrm{mg}$ of 1-bis(4-methoxyphenyl)amino-2triisopropylsilylacetylene $\mathbf{2}$ as white crystals: yield $41 \%$. mp. $116^{\circ} \mathrm{C} .{ }^{1} \mathrm{H}$ NMR (500 MHz, $\mathrm{CDCl}_{3}$; ppm) 反 7.21-6.85 (m, 8H), $3.79(\mathrm{~s}, 6 \mathrm{H}), 1.07(\mathrm{~s}, 21 \mathrm{H}) ;{ }^{13} \mathrm{C}$ NMR $\left(\mathrm{CDCl}_{3} ; \mathrm{ppm}\right) \delta 156.0,136.9,121.9,114.4$, 103.4, 63.0, 55.6, 18.8, 11.7. IR ( $\mathrm{KBr}$ pellet, $\mathrm{cm}^{-1}$ ) $2149\left(v_{\mathrm{C} \equiv \mathrm{C}}\right)$; MS (EI) m/e 409, calcd for $\mathrm{C}_{25} \mathrm{H}_{35^{-}}$ $\mathrm{NO}_{2} \mathrm{Si}$ 409.6. Anal. calcd for $\mathrm{C}_{25} \mathrm{H}_{35} \mathrm{NO}_{2} \mathrm{Si}$ : C, 73.3; H, 8.6; N, 3.4; Found: C, 73.6; H, 8.3; N, 3.3.

\section{Bis(4-methoxyphenyl)aminoacetylene 3}

To a solution of 1-bis(4-methoxyphenyl)amino-2triisopropylsilylacetylene $(51.0 \mathrm{mg}, 0.124 \mathrm{mmol})$ in THF $(1.2 \mathrm{~mL})$ at $-10^{\circ} \mathrm{C}$ was added tetrabutylammonium fluoride $(0.248 \mathrm{~mL}$ of a $1.0 \mathrm{M}$ solution in anhydrous THF, $0.248 \mathrm{mmol}$ ). The reaction was stirred at $-10^{\circ} \mathrm{C}$ for $5 \mathrm{~min}$ and warmed to room temperature. The reaction was quenched with saturated aqueous $\mathrm{NH}_{4} \mathrm{Cl}$, extracted with ether, dried over $\mathrm{Na}_{2} \mathrm{SO}_{4}$, and evaporated to give the crude product, which was purified using HPLC to afford $15.1 \mathrm{mg}$ of bis(4-methoxyphenyl)aminoacetylene as white crystals: yield $49 \%$. mp. $108^{\circ} \mathrm{C} .{ }^{1} \mathrm{H}$ NMR $\left(500 \mathrm{MHz}, \mathrm{CDCl}_{3} ; \mathrm{ppm}\right)$

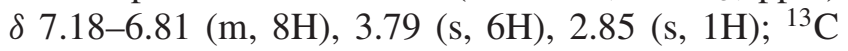
NMR $\left(\mathrm{CDCl}_{3} ; \mathrm{ppm}\right) \delta 123.0,117.4,117.0,114.7$, 82.9, 80.6, 55.6. IR ( $\mathrm{KBr}$ pellet, $\left.\mathrm{cm}^{-1}\right) 2121\left(v_{\mathrm{C} \equiv \mathrm{C}}\right)$; MS (EI) $m / e$ 253, calcd for $\mathrm{C}_{16} \mathrm{H}_{15} \mathrm{NO}_{2}$ 253.3. Anal. calcd for $\mathrm{C}_{16} \mathrm{H}_{15} \mathrm{NO}_{2}$ : C, 75.9; H, 6.0; N, 5.5; Found: C, 76.1; H, 6.2; N, 5.5.

\section{1-Methyl-2-bis(4-methoxyphenyl)aminoacetylene 4}

To a solution of bis(4-methoxyphenyl)aminoacetylene $(20.0 \mathrm{mg}$. $78.9 \mu \mathrm{mol})$ in anhydrous THF $(0.8$ $\mathrm{mL})$ at $-78^{\circ} \mathrm{C}$ was added $n$-butyllithium $(750 \mu \mathrm{L}$ of a $1.58 \mathrm{M}$ solution in THF, $118 \mu \mathrm{mol}$ ) dropwise over $5 \mathrm{~min}$. The mixture was slowly warmed to $-40^{\circ} \mathrm{C}$ for $1 \mathrm{~h}$, methyl iodide $(44.7 \mathrm{mg}, 316 \mu \mathrm{mol})$ was added 
dropwise over $15 \mathrm{~min}$ and slowly warmed to room temperature. The reaction mixture was quenched with aqueous $\mathrm{NH}_{4} \mathrm{Cl}$, extracted with ether, dried over $\mathrm{Na}_{2} \mathrm{SO}_{4}$, and evaporated to give the crude product, which was purified using HPLC to afford $11.2 \mathrm{mg}$ of 1-methyl-2-bis(4-methoxyphenyl)aminoacetylene $\mathbf{4}$ as white crystals: yield $53 \%$. mp. $110^{\circ} \mathrm{C} .{ }^{1} \mathrm{H}$ NMR (500 $\mathrm{MHz}, \mathrm{CDCl}_{3}$; ppm) $\delta 6.82(\mathrm{~d}, J=8.9 \mathrm{~Hz}, 4 \mathrm{H}), 6.42$ $(\mathrm{d}, J=8.9 \mathrm{~Hz}, 4 \mathrm{H}), 3.80(\mathrm{~s}, 6 \mathrm{H}), 2.16(\mathrm{~s}, 3 \mathrm{H}) ;{ }^{13} \mathrm{C}$ NMR $\left(\mathrm{CDCl}_{3} ; \mathrm{ppm}\right) \delta 154.2,137.9,119.5,114.7$, 85.9, 74.8, 55.6, 13.3. IR ( $\mathrm{KBr}$ pellet, $\left.\mathrm{cm}^{-1}\right) 2215$ $\left(v_{\mathrm{C} \equiv \mathrm{C}}\right)$; MS (EI) $m / e$ 267, calcd for $\mathrm{C}_{16} \mathrm{H}_{15} \mathrm{NO}_{2}$ 267.2. Anal. calcd for $\mathrm{C}_{17} \mathrm{H}_{17} \mathrm{NO}_{2}$ : C, 76.3; H, 6.4; N, 5.2; Found: C, 76.1; H, 6.6; N, 5.1.

\section{t-Butyl-bis(4-methoxyphenyl)amine 6}

To a $5 \mathrm{~mL}$ toluene solution of $p$-bromoanisole (467 $\mathrm{mg}, 2.66 \mathrm{mmol})$, $t$-butylamine (183 $\mathrm{mg}, 2.66 \mathrm{mmol})$, tris(dibenzylidene-acetone)dipalladium $\quad(11.4 \mathrm{mg}$, $39.9 \mu \mathrm{mol}$ ), (S)-(-)-2,2'-bis(diphenylphosphino)-1,1'binaphtyl $(8.46 \mathrm{mg}, 120 \mu \mathrm{mol})$, and sodium $t$-butoxide (336 mg, $3.72 \mathrm{mmol}$ ) were added, and the mixture was stirred for $20 \mathrm{~h}$ at $80^{\circ} \mathrm{C}$ under nitrogen, and then cooled to room temperature. The crude product was extracted with chloroform, washed with water, and dried over anhydrous magnesium sulfate. The solvent was removed in vacuo and the residue was purified using HPLC to afford $136 \mathrm{mg}$ of $t$-butyl-(4-methoxyphenyl)amine as a colorless oil: yield $33 \% .{ }^{1} \mathrm{H}$ NMR $\left(500 \mathrm{MHz}, \mathrm{CDCl}_{3} ; \mathrm{ppm}\right) \delta 6.82-6.75(\mathrm{~m}, 4 \mathrm{H}), 3.75(\mathrm{~s}$, $3 \mathrm{H}), 2.87(\mathrm{~s}, 1 \mathrm{H}), 1.23(\mathrm{~s}, 9 \mathrm{H}) ;{ }^{13} \mathrm{C} \mathrm{NMR}\left(\mathrm{CDCl}_{3}\right.$; ppm) $\delta 154.3,139.7,122.8,114.0,55.4,52.2,30.1$. IR $\left(\mathrm{NaCl}, \mathrm{cm}^{-1}\right) 3393\left(v_{\mathrm{N}-\mathrm{H}}\right), 1362\left(v_{\mathrm{C}-\mathrm{N}}\right)$; MS (EI) $m / e 179$ calcd for $\mathrm{C}_{11} \mathrm{H}_{17} \mathrm{NO}$ for 179.3. Anal. calcd for $\mathrm{C}_{11} \mathrm{H}_{17} \mathrm{NO}$ : $\mathrm{C}, 73.7 ; \mathrm{H}, 9.6$; $\mathrm{N}, 7.8$. Found: $\mathrm{C}$, 74.0; H, 9.5; N, 7.7.

To a $1.4 \mathrm{~mL}$ toluene solution of $t$-butyl-(4-methoxyphenyl)amine (100 mg, $0.588 \mathrm{mmol}), p$-bromoanisole (104 mg, $0.588 \mathrm{mmol})$, tris(dibenzylidene-acetone)dipalladium $(2.55 \mathrm{mg}, 2.79 \mu \mathrm{mol}),(S)-(-)-2,2^{\prime}$-bis(diphenylphosphino)-1,1'-binaphtyl (1.67 mg, 5.58 $\mu \mathrm{mol})$, and sodium $t$-butoxide $(75.2 \mathrm{mg}, 0.781 \mathrm{mmol})$ were added, and the mixture was stirred for $20 \mathrm{~h}$ at $80^{\circ} \mathrm{C}$ under nitrogen, and then cooled to room temperature. The crude product was extracted with chloroform, washed with water, and dried over anhydrous magnesium sulfate. The solvent was removed in vacuo and the residue was purified using HPLC to afford $35.0 \mathrm{mg}$ of $t$-butyl-bis(4-methoxyphenyl)amine 6 as white crystals: yield $22 \%$. mp. $108^{\circ} \mathrm{C} .{ }^{1} \mathrm{H}$ $\operatorname{NMR}\left(500 \mathrm{MHz}, \mathrm{CDCl}_{3} ; \mathrm{ppm}\right) \delta 7.03(\mathrm{~d}, J=9.0 \mathrm{~Hz}$, 2H), $6.75(\mathrm{~d}, J=9.0 \mathrm{~Hz}, 2 \mathrm{H}), 3.80(\mathrm{~s}, 6 \mathrm{H}), 1.32(\mathrm{~s}$, 9H); ${ }^{13} \mathrm{C}$ NMR $\left(\mathrm{CDCl}_{3}\right.$; ppm) $\delta 154.2,137.9,119.5$, 114.7, 55.6, 47.3, 32.5. IR ( $\mathrm{KBr}$ pellet, $\left.\mathrm{cm}^{-1}\right) 1362$ $\left(v_{\mathrm{C}-\mathrm{N}}\right)$; MS (EI) $m / e 285$ calcd for $\mathrm{C}_{18} \mathrm{H}_{23} \mathrm{NO}_{2}$ for
285.4. Anal. calcd for $\mathrm{C}_{18} \mathrm{H}_{23} \mathrm{NO}_{2}$ : C, 75.8; H, 8.1; N, 4.9. Found: C, 75.4; H, 8.3; N, 4.6.

\section{Other Materials}

Tri(4-methoxyphenyl)amine $\mathbf{5}$ was prepared according to the literature. ${ }^{11}$ The other reagents were used as received. The solvents were purified in the usual way.

\section{Polymerization}

To a monomer solution was added a polymerization catalyst under a nitrogen atmosphere. The polymerization mixture was poured into a large excess of methanol to precipitate the polymer. It was separated by filtration and washed with methanol. The polymer powder was redissolved in dichloromethane and then reprecipitated into methanol. The filtered polymer was dried under reduced pressure. Gel permeation chromatography was performed with chloroform as an eluent and polystyrene as a standard using a TOSOH HLC-8220 instrument.

\section{Magnetic Measurements}

The $\mathrm{SbCl}_{6}{ }^{-}$salt of $\mathbf{1}^{+}$was dissolved in the methylene chloride solution of poly(styrenesulfonate tetrabutylammonium), and then the solvent was thoroughly removed to give the diluted sample. The diluted sample was transferred to a diamagnetic plastic capsule after oxidation. The magnetization and static magnetic susceptibility were measured using a Quantum Design MPMS-7 SQUID magnetometer. The magnetization was measured from 0.1 to $7 \mathrm{~T}$ at $1.8,2.0,2.5,3.0$, and $5.0 \mathrm{~K}$. The static magnetic susceptibility was measured from 1.8 to $100 \mathrm{~K}$ in a $0.5 \mathrm{~T}$ field. The ferromagnetic magnetization ascribed to the impurities was determined by the Honda-Owen plots to be very low $(<1 \mathrm{ppm})$ and subtracted from the overall magnetization. The diamagnetic susceptibility of the diluent and capsule was estimated by the Curie plots of magnetic susceptibility. The corrected magnetization data was fitted to Brillouin functions using the self-consistent version of the mean field approximation. ${ }^{12}$

\section{Other Measurements}

Cyclic voltammetry was carried out using a BAS $100 \mathrm{~B} / \mathrm{W}$ electrochemical analyzer in the methylene chloride solution with $0.1 \mathrm{M}\left(\mathrm{C}_{4} \mathrm{H}_{9}\right)_{4} \mathrm{NBF}_{4}$ as a supporting electrolyte. A platinum working electrode and commercial $\mathrm{Ag} / \mathrm{AgCl}$ electrode as the reference were used. The ESR spectra were taken using a JEOL JES-2XG ESR spectrometer with 100-kHz field modulation. The IR, NMR, mass, and UV spectra were measured using JASCO FT/IR-410, JEOL NMR $500 \Lambda$, Shimadzu GC-MS 17A, and JASCO V-550 spectrometers, respectively. 


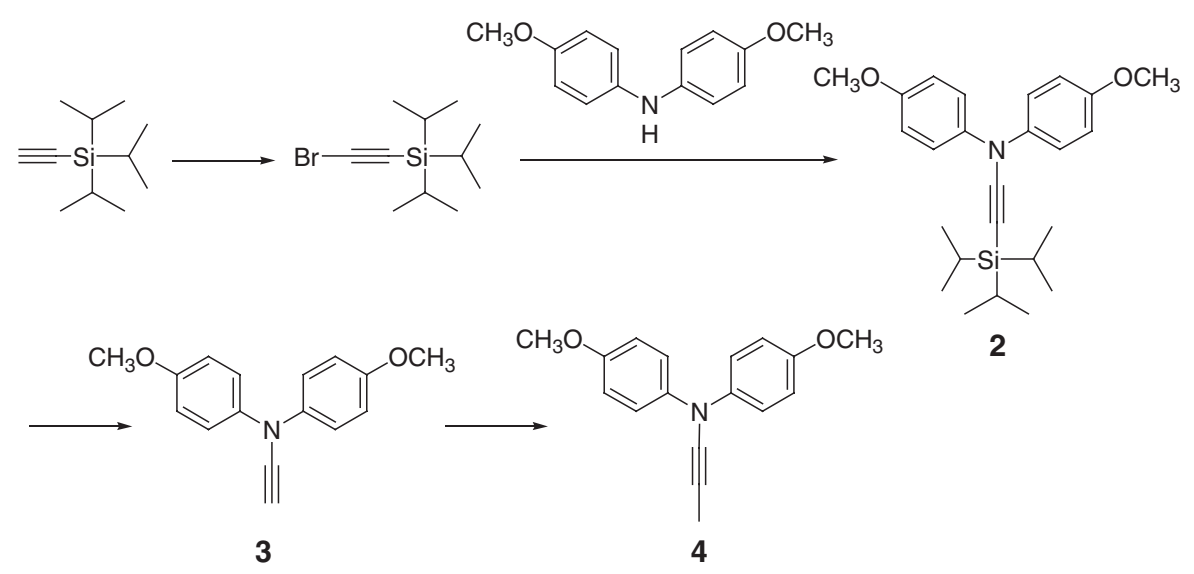

Scheme 1.<smiles>C#CN(c1ccc(OC)cc1)c1ccc(OC)cc1</smiles>

3<smiles>CC#CN(c1ccc(OC)cc1)c1ccc(OC)cc1</smiles>

4<smiles>CC=CN(c1ccc(OC)cc1)c1ccc(OC)cc1</smiles>

$1 \mathrm{a}$<smiles>CC=C(C)N(c1ccc(OC)cc1)c1ccc(OC)cc1</smiles>

1b

Scheme 2.

\section{RESULTS AND DISCUSSION}

The acetylenic monomers, bis(4-methoxyphenyl)aminoacetylene 3 and 1-methyl-2-bis(4-methoxyphenyl)aminoacetylene 4, were synthesized via Scheme 1. Each para-position of the phenylamine group is protected with a methoxy group in order to inhibit the dimerization and/or disproportionation reaction of the formed aminium cation radical. Bis(4-methoxyphenyl)amine was cross-coupled with 1-bromo-2-triisopropylsilylethyne using a catalyst of palladium(II) acetate and bis(2-diphenylphosphinophenyl)ether to give 1-bis(4-methoxyphenyl)amino-2-triisopropylsilylacetylene 2 . The deprotection of the silyl group using tetrabutylammonium fluoride at $-10^{\circ} \mathrm{C}$ led to the monomer 3. The introduction of a methyl group into 3 using methyl iodide afforded the monomer 4.

Substituted acetylenes have been polymerized with the chlorides of the group 5 or 6 transition metals or $\mathrm{Rh}$ complexes (Scheme 1). ${ }^{4}$ At first, 3 was polymerized using the $[\mathrm{Rh} \text { (norbornadiene) } \mathrm{Cl}]_{2}$ complex which had been reported to be an effective catalyst for the polymerization of nitrogen-containing acetylenic monomers. ${ }^{13}$ The reaction catalyzed with the Rh complex in triethylamine, however, yielded only an oligomeric product (Table I). Masuda et al. prepared and reported that the mixtures of $\mathrm{WCl}_{6}-\mathrm{Ph}_{4} \mathrm{Sn}, \mathrm{TaCl}_{5}-$ $\mathrm{Ph}_{4} \mathrm{Sn}$, and $\mathrm{NbCl}_{5}-\mathrm{Ph}_{4} \mathrm{Sn}$ are active catalysts for the metathesis polymerization of acetylenes having bulky groups. ${ }^{14}$ The polymerization of $\mathbf{3}$ was carried out using with these catalysts. The polymerization of $\mathbf{3}$ using the $\mathrm{WCl}_{6}-\mathrm{Ph}_{4} \mathrm{Sn}$ mixture in toluene at $80^{\circ} \mathrm{C}$ yielded a brownish powder 1a. The polymer 1a was soluble in chloroform and toluene (partly), and its molecular weight was 2,700 . The IR spectrum of 1a clearly indicated the complete disappearance of the stretching vibration of the $\mathrm{C} \equiv \mathrm{C}$ bond and the $\equiv \mathrm{CH}$ bond attributed to the acetylenic monomer $\mathbf{3}$ and the appearance of an out-of-plane bending mode of the $=\mathrm{CH}$ bond to the polyene backbone. ${ }^{1} \mathrm{H}$ NMR spectrum also supported the structure of 1a; broad peaks at $\delta 3.8$ and 7.0 assigned to the methoxy and phenyl or methine protons, respectively, and no peak around $\delta 2.9$ ascribed to an acetylenic proton in the spectrum of the polymer 1a.

The polymerization of $\mathbf{4}$ was also examined using 
Table I. Polymerization of the acetylenic monomers, 3 and $\mathbf{4}$

\begin{tabular}{|c|c|c|c|c|c|c|c|c|c|c|}
\hline Monomer & Entry & Catalyst & Cocatalyst & $\begin{array}{c}{[\mathrm{M}]_{0}} \\
(\mathrm{~mol} / \mathrm{L})\end{array}$ & Solvent & $\begin{array}{l}\text { Temp } \\
\left({ }^{\circ} \mathrm{C}\right)\end{array}$ & $\begin{array}{l}\text { Time } \\
\text { (h) }\end{array}$ & $\begin{array}{l}\text { Yield } \\
\text { (wt \%) }\end{array}$ & $M_{\mathrm{n}}{ }^{\mathrm{a}}$ & $M_{\mathrm{w}} / M_{\mathrm{n}}$ \\
\hline \multirow{5}{*}{3} & 1 & {$[\mathrm{Rh}(\mathrm{nbd}) \mathrm{Cl}]_{2}$} & - & 0.2 & toluene & 60 & 24 & 46 & 1,100 & 1.5 \\
\hline & 2 & $\mathrm{MoCl}_{5}$ & $\mathrm{SbPh}_{3}$ & 0.1 & toluene & r.t. & 24 & 10 & 970 & 1.1 \\
\hline & 3 & $\mathrm{WCl}_{6}$ & $\mathrm{Ph}_{4} \mathrm{Sn}$ & 0.2 & toluene & 50 & 18 & 64 & 2,700 & 1.3 \\
\hline & 4 & $\mathrm{TaCl}_{5}$ & $\mathrm{Ph}_{4} \mathrm{Sn}$ & 0.2 & toluene & 50 & 18 & 52 & 1,400 & 1.3 \\
\hline & 5 & $\mathrm{NbCl}_{5}$ & $\mathrm{Ph}_{4} \mathrm{Sn}$ & 0.1 & toluene & 80 & 24 & 65 & 2,100 & 1.2 \\
\hline \multirow{4}{*}{4} & 1 & {$[\mathrm{Rh}(\mathrm{nbd}) \mathrm{Cl}]_{2}$} & - & 0.5 & triethylamine & r.t. & 24 & 26 & 650 & 1.3 \\
\hline & 2 & $\mathrm{TaCl}_{5}$ & $\mathrm{Ph}_{4} \mathrm{Sn}$ & 0.1 & toluene & 50 & 24 & 30 & 960 & 1.6 \\
\hline & 3 & $\mathrm{NbCl}_{5}$ & $\mathrm{Ph}_{4} \mathrm{Sn}$ & 0.1 & toluene & 50 & 24 & 33 & 2,100 & 1.4 \\
\hline & 4 & $\mathrm{NbCl}_{5}$ & $\mathrm{Ph}_{4} \mathrm{Sn}$ & 0.1 & toluene & 80 & 24 & 29 & 790 & 1.3 \\
\hline
\end{tabular}

${ }^{\mathrm{a}}$ Measured by GPC calibrated with polystyrene standard.

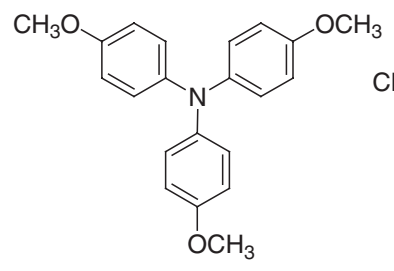

5

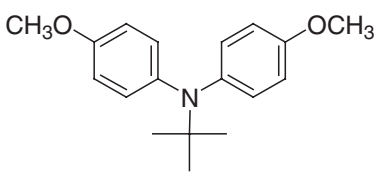

6
Chart 2.

[Rh(norbornadiene) $\mathrm{Cl}]_{2}, \mathrm{TaCl}_{5}-\mathrm{Ph}_{4} \mathrm{Sn}$, and $\mathrm{NbCl}_{5}-$ $\mathrm{Ph}_{4} \mathrm{Sn} . \mathrm{NbCl}_{5}$ was the most effective catalyst for $\mathbf{4}$ to yield $\mathbf{1 b}$ with a molecular weight of 2,100. 1b was soluble in chloroform, toluene, and THF. The chloroform solution of $\mathbf{1 a}$ and $\mathbf{1 b}$ showed two UV/ vis absorption maxima at 305 and $430 \mathrm{~nm}$ and 300 and $440 \mathrm{~nm}$, respectively, which were longer than those of $\mathbf{3}$ and $\mathbf{4}$, suggesting some $\pi$-conjugation in the polymer 1 .

The redox properties of the model aryl amine compounds, tris(4-methoxyphenyl)amine $\mathbf{5}$ and $t$-butylbis(4-methoxyphenyl)amine 6, were electrochemically studied. The cyclic voltammograms of $\mathbf{5}$ and $\mathbf{6}$ at different scan rates showed a completely reversible oxidation and reduction process (Figure 1). The redox potentials $\left(E_{\mathrm{p}}{ }^{1 / 2}=\left(E_{\mathrm{p}}{ }^{\mathrm{a}}+E_{\mathrm{p}}{ }^{\mathrm{c}}\right) / 2\right)$ and the potential separations between the oxidation and reduction peaks $\left(\Delta E_{\mathrm{p}}{ }^{\mathrm{a}-\mathrm{c}}=E_{\mathrm{p}}{ }^{\mathrm{a}}-E_{\mathrm{p}}{ }^{\mathrm{c}}\right)$ were estimated and listed in Table II. The redox potentials for $\mathbf{5}$ and $\mathbf{6}$ were 0.62 and $0.72 \mathrm{~V}$, respectively; the latter was anodically shifted due to the electro-donating effect of the $t$-butyl and 4-methoxyphenyl substituted groups.

The heterogeneous electron-transfer rate constant $\left(k_{0}\right)$ for the oxidation of the model amines was estimated using Nicholson's method. ${ }^{15}$ The diffusion coefficient $(D)$ of the amines was calculated from the slope of the diffusion-limited current at a rotating disc electrode. The $k_{0}$ and $D$ values were given in Table II. The rate constants of $\mathbf{5}$ and $\mathbf{6}$ were approximately $10^{-2}-10^{-3} \mathrm{~cm} / \mathrm{s}$, which indicated a sufficiently fast

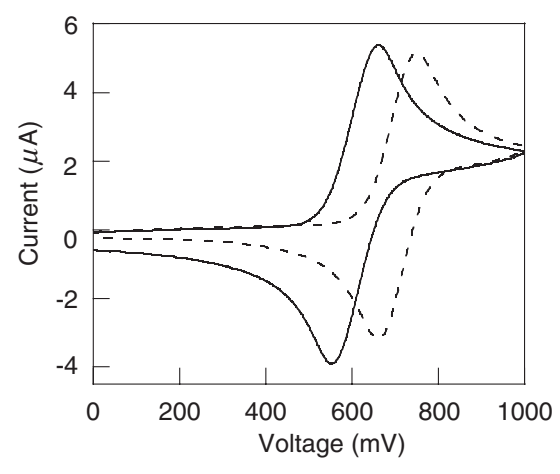

Figure 1. Cyclic voltammograms of the model aryl amine compounds 5 (-) and 6 (---) in a methylene chloride solution at a sweep rate of $100 \mathrm{mV} / \mathrm{s}$.

Table II. Standard rate constant and diffusion coefficient for the model aryl amine compounds of $\mathbf{5}$ and $\mathbf{6}$

\begin{tabular}{ccccc}
\hline & $E_{\mathrm{p}}{ }^{1 / 2} / \mathrm{V}$ & $\Delta E_{\mathrm{p}}{ }^{\mathrm{a}-\mathrm{c}} / \mathrm{V}$ & $D / \mathrm{cm}^{2} \mathrm{~s}^{-1}$ & $k_{0} / \mathrm{cm} \mathrm{s}^{-1}$ \\
\hline $\mathbf{5}$ & 0.61 & 0.107 & $1.7 \times 10^{-5}$ & $7.0 \times 10^{-3}$ \\
$\mathbf{6}$ & 0.72 & 0.093 & $2.4 \times 10^{-5}$ & $1.3 \times 10^{-2}$ \\
\hline
\end{tabular}

electron-transfer process for these model aryl amine derivatives. The replacement of the 4-methoxyphenyl group with the $t$-butyl group led to the higher $k_{0}$ value of 6 . These results mean that the aminium cation radicals are chemically stable even at room temperature and that the radical generation is not accompanied by any subsequent side reactions.

Cyclic voltammetry of the polymers $\mathbf{1}$ in a methylene chloride solution gave also unimodal but broaden waves (Figure 2). Peak integration of the reduction wave for 1a was smaller than that of the oxidation wave (Inset of Figure 2), which suggested a side reaction on the polyacetylenic backbone after the generation of the cation radical for 1a. On the other hand, the cyclic voltammogram of $\mathbf{1 b}$ showed the reversible redox wave given in Figure 2. This suggested that the introduction of the methyl group upon the polyacetylenic backbone inhibited the side reaction and signifi- 


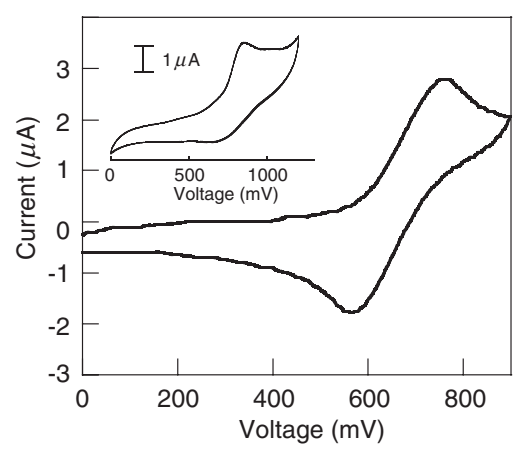

Figure 2. Cyclic voltammogram of polymer $\mathbf{1 b}$ in a methylene chloride solution at a sweep rate of $100 \mathrm{mV} / \mathrm{s}$. Inset: cyclic voltammogram of polymer 1a.

cantly enhanced the chemical stability of the poly(aminium radical). The redox potentials for 1a and 1b were 0.75 and $0.67 \mathrm{~V}$, respectively; the latter was cathodically shifted by the introduction of the methyl group onto the polyacetylenic backbone.

The triaryl aminium cation radical salts or the salts of the poly(aminium radical) $\mathbf{1}^{+}$were prepared by oxidizing the corresponding polymer 1 with $\mathrm{SbCl}_{5}$ and isolated as blue powders. ${ }^{16}$ The color of the methylene chloride solution of $\mathbf{1}$ turned from brown to deep blue, which is characteristic of aminium cation radicals. ${ }^{8 a, 17}$ The spin concentrations of $\mathbf{1 a}^{+}$and $\mathbf{1} \mathbf{b}^{+}$were estimated to be 0.24 and $0.56 \mathrm{spin} / \mathrm{unit}$, respectively. The half-life $(\tau)$ in solution of the aminium radical $\mathbf{1} \mathbf{b}^{+}$ ( $\tau=4 \mathrm{~d}$ ) was longer than that of $\mathbf{1 a}^{+}(\tau=2 \mathrm{~d})$, indicating the introduction effect of the methyl group to inhibit the dimerization and/or disproportionation reaction of the formed aminium cation radical. The halflife of $\mathbf{1} \mathbf{b}^{+}$in the powder state was $10 \mathrm{~d}$ at room temperature, which showed the excellent chemical stability of the poly(aminium radical).

The solution ESR gave a unimodal spectrum at $g=$ 2.0032 and $g=2.0031$ with a peak-to-peak width of 1.3 and $1.2 \mathrm{mT}$ for $\mathbf{1 a}^{+}$and $\mathbf{1 b}^{+}$, respectively (for $\mathbf{1 a}^{+}$, see the inset of Figure 3). These ESR spectra indicate a nitrogen-centered radical formation. ${ }^{10}$ The ESR study at cryogenic temperature gave a spectrum ascribed to $\Delta M_{\mathrm{s}}= \pm 2$ (half-field and forbidden) transition at $160 \mathrm{mT}$ for $\mathbf{1 a}^{+}$(see the inset of Figure 3). The signal intensity of the $\Delta M_{\mathrm{s}}= \pm 2$ transition of $\mathbf{1 a}^{+}$was proportional to the reciprocal of the temperature and followed Curie's law (Figure 3). This result means a triplet ground state with a large triplet-singlet energy gap for poly(aminium radical) (however, it does not rule out the possibility of a degenerate singlet-triplet state).

The $\mathrm{SbCl}_{6}{ }^{-}$salts of the poly(aminium radical)s $\mathbf{1}^{+}$were diluted in the presence of poly(styrenesulfonate tetrabutylammonium) as a diamagnetic diluent to reduce the antiferromagnetic interaction through

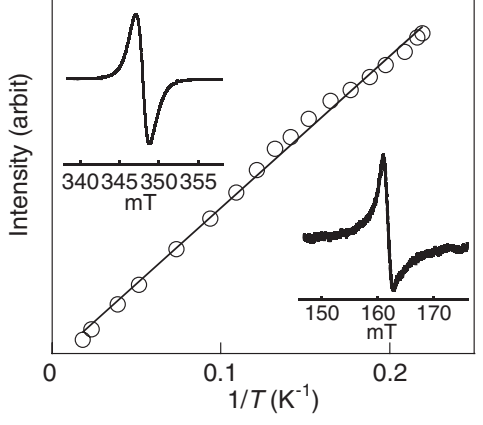

Figure 3. Temperature dependency of the ESR signal intensity of the $\Delta M_{\mathrm{s}}= \pm 2$ transition of poly(aminium radical) $\mathbf{1 a}^{+}$ in methylene chloride. The solid line is a least-square fitting to Curie's law (Intensity $=\mathrm{C} / T$ ). Inset: ESR spectra of the $\mathbf{1 a}^{+}$at room temperature, and the $\Delta M_{\mathrm{s}} \pm 2$ spectrum of $\mathbf{1 a}^{+}$in methylene chloride at $20 \mathrm{~K}$.

space. ${ }^{10 \mathrm{~d}}$ Poly(styrenesulfonate tetrabutylammonium) is a polyanion but soluble in methylene chloride. After adding the solution of poly(styrenesulfonate tetrabutylammonium) to the methylene chloride solution of the $\mathbf{1}^{+}$, the mixture became suspended, suggesting the polycation/polyanion complex formation. These diluted samples of $\mathbf{1}^{+}$were subjected to static magnetic susceptibility $(\chi)$ and magnetization $(M)$ measurements using a SQUID magnetometer. $\chi$ was normalized to the $\chi_{\text {mol }}$ value with the radical concentration in the sample determined by the saturation magnetization $\left(M_{\mathrm{s}}\right)$ of $M v s$. the magnetic field $(H)$ plots. The normalized plots of the magnetization $\left(M / M_{\mathrm{s}}\right)$ for the diluted $\mathbf{1 a}^{+}$was close to the Brillouin curve for $3 / 2$ with the spin concentration $=0.25 \mathrm{spin} /$ unit and $\mathrm{DP}=11$. The $\chi_{\mathrm{mol}} T$ plots leveled off in the temperature range from 20 to $100 \mathrm{~K}$ (see inset of Figure 4). The flat $\chi_{\mathrm{mol}} T$ plot means the multiplet ground state for $\mathbf{1 a}^{+}$with a large triplet-singlet energy gap $(\gg 100 \mathrm{~K})$ and that $\mathbf{1 a}^{+}$is a high-spin purely organic molecule with $S=3 / 2$.

The normalized plots of the magnetization $\left(M / M_{\mathrm{s}}\right)$ for the diluted $\mathbf{1 b}^{+}$was close to the Brillouin curve for $4 / 2$ with the spin concentration $=0.52 \mathrm{spin} /$ unit and $\mathrm{DP}=7$. This result would be explained by the higher spin concentration of $\mathbf{1} \mathbf{b}^{+}$derived from the introduction of a methyl group on the polyacetylene backbone. A ferromagnetic and intramolecular spin-alignment is realized between the unpaired electrons of the poly(aminium radical) even through the polyacetylene backbone as well as the polyphenylenevinylene backbone. ${ }^{6}$ Taking into account both the molecular weight or DP and the spin concentration of $\mathbf{1}^{+}$, all the pendant radical spins in each polymer chain are considered to be aligned. Both the small repeating unit of polyacetylene (the number of carbons between the substituted radicals is three) and the delocalized spin density of an aryl aminium cation radical could en- 


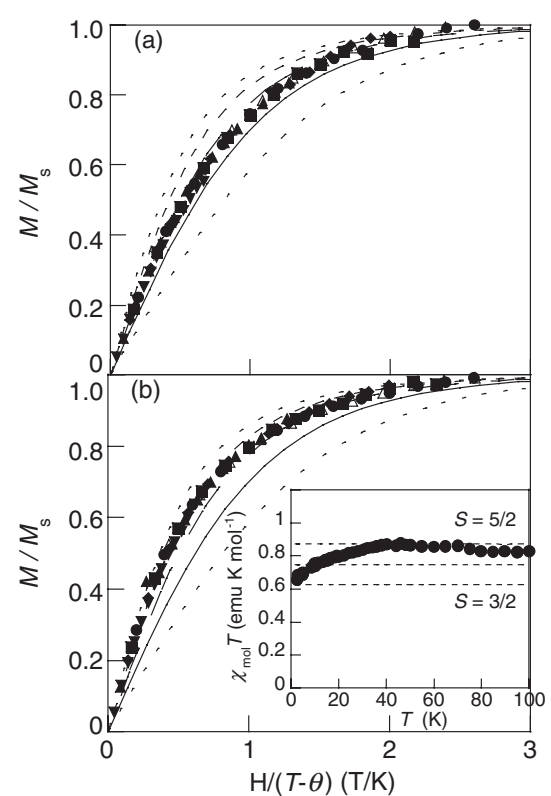

Figure 4. (a) Normalized plots of magnetization $\left(M / M_{\mathrm{s}}\right) v s$. the ratio of the magnetic field and temperature $(H /(T-\theta))$ for the diluted poly(aminium radical) $\mathbf{1 a}^{+}(\mathrm{DP}=11)$ with the spin concentration $=0.25 \mathrm{spin} /$ amine unit at $1.8(\bigcirc), 2.0(\bullet), 2.5$ $(\square), 3.0(\square)$, and $5.0(\diamond) \mathrm{K}(\theta=-0.4 \mathrm{~K})$ and theoretical curves corresponding to $S=1 / 2,2 / 2,3 / 2,4 / 2$, and 5/2. (b) Normalized plots of magnetization $\left(M / M_{\mathrm{s}}\right)$ vs. the ratio of the magnetic field and temperature $(H /(T-\theta))$ for the diluted poly(aminium radical) $\mathbf{1} \mathbf{b}^{+}(\mathrm{DP}=7)$ with the spin concentration $=0.52 \mathrm{spin} /$ amine unit at $1.8(\bigcirc), 2.0(\bullet), 2.5(\square), 3.0(\square)$, and $5.0(\diamond) \mathrm{K}(\theta=$ $-0.4 \mathrm{~K}$ ). Inset: $\chi_{\mathrm{mol}} T$ vs. $T$ plots for the diluted sample of $\mathbf{1 b}^{+}$.

hance the interaction between the pendant unpaired electrons. $S$ is expected to proportionally increase with the DP of the poly(aminium radical) $\mathbf{1}^{+}$by changing the combination of a catalyst and a co-catalyst.

Acknowledgment. This work was partially supported by Grants-in-Aids for Scientific Research and the COE Programs "Practical Nano-Chemistry" and "Molecular Nano-Engineering" from MEXT, Japan.

\section{REFERENCES}

1. (a) P. M. Lahti, "Magnetic Properties of Organic Materials," Marcel Dekker, New York, 1999.

(b) K. Itoh and M. Kinoshita, "Molecular Magnetism: New Magnetic Materials," Kohdansha and Gordon \& Breach, Tokyo and Amsterdam, 2000.

(c) J. Veciana, " $\pi$-Electron Magnetism From Molecules to Magnetic Materials," Springer, Berlin, 2001.

(d) J. S. Miller and M. Drillon, "Magnetism: Molecules to Materials III," Wiley-VCH, Weinheim, 2002.

2. W. T. Borden and E. R. Davidson, J. Am. Chem. Soc., 99, 4587 (1977).

3. (a) I. A. Misurkin and A. A. Ovchinnikov, Russ. Chem. Rev., 46, 967 (1977). (b) H. Iwamura and N. Koga, Acc. Chem. Res., 26, 346 (1993).

(c) A. Rajca, Chem. Rev., 94, 871 (1994).

(d) H. Nishide, Adv. Mater., 7, 937 (1995).

(e) A. Rajca, Chem. Eur. J., 8, 4834 (2002).

(f) T. Itoh, Y. Jinbo, K. Hirai, and H. Tomioka, J. Am. Chem. Soc., 127, 1650 (2005).

4. (a) T. Masuda, S. M. A. Karim, and R. Nomura, J. Mol. Catal. A: Chem., 160, 125 (2000).

(b) K. Nagai, T. Masuda, T. Nakagawa, B. D. Freeman, and I. Pinnau, Prog. Polym. Sci., 26, 721 (2001).

(c) F. Sanda, T. Kawaguchi, and T. Masuda, Macromolecules, 36, 2224 (2003).

5. (a) H. Nishide, N. Yoshioka, M. Igarashi, and E. Tsuchida, Macromolecules, 21, 3319 (1988).

(b) H. Nishide, N. Yoshioka, K. Inagaki, T. Kaku, and E. Tsuchida, Macromolecules, 25, 569 (1992).

(c) H. Nishide, T. Kaneko, N. Yoshioka, H. Akiyama, M. Igarashi, and E. Tsuchida, Macromolecules, 26, 4567 (1993).

(d) N. Yoshioka, H. Nishide, T. Kaneko, H. Yoshiki, and E. Tsuchida, Macromolecules, 25, 3838 (1992).

(e) E. Fukuzaki, N. Takahashi, S. Imai, H. Nishide, and A. Rajca, Polym. J., 37, 284 (2005).

(f) Y. Miura, M. Matsumoto, Y. Ushitani, Y. Teki, T. Takui, and K. Itoh, Macromolecules, 26, 6673 (1993).

(g) T. Kaneko, T. Yamamoto, T. Aoki, and E. Oikawa, Chem. Lett., 623 (1999).

6. H. Nishide, T. Kaneko, M. Igarashi, E. Tsuchida, N. Yoshioka, and P. M. Lahti, Macromolecules, 27, 3082 (1994).

7. (a) R. I. Walter, J. Am. Chem. Soc., 77, 5999 (1955).

(b) E. T. Seo, R. F. Nelson, J. M. Fitsch, L. S. Marcoux, D. W. Leedy, and R. N. Adams, J. Am. Chem. Soc., 88, 3498 (1966).

(c) L. Hagopian, K. Günyer, and R. I. Walter, J. Phys. Chem., 71, 2290 (1967).

(d) S. Sasaki and M. Iyoda, Chem. Lett., 1011 (1995).

8. (a) W. Schmidt and E. Steckhan, Chem. Ber., 113, 577 (1980).

(b) E. Steckhan, Top. Curr. Chem., 142, 1 (1987).

9. (a) K. Yoshizawa, A. Chano, A. Ito, K. Tanaka, T. Yamabe, H. Fujita, and J. Yamauchi, Chem. Lett., 369 (1992).

(b) K. Yoshizawa, A. Chano, A. Ito, K. Tanaka, T. Yamabe, H. Fujita, J. Yamauchi, and M. Shiro, J. Am. Chem. Soc., 114, 5994 (1992).

(c) K. R. Stickley and S. C. Blackstock, J. Am. Chem. Soc., 116, 11576 (1994).

(d) K. R. Stickley and S. C. Blackstock, Tetrahedron Lett., 36, 1585 (1995).

(e) M. Yano, M. Furuichi, K. Sato, D. Shiomi, A. Ichimura, K. Abe, T. Takui, and K. Itoh, Synth. Met., 85, 1665 (1997). (f) K. Sato, M. Yano, M. Furuichi, D. Shiomi, T. Takui, K. Abe, K. Itoh, A. Highchi, K. Katsuma, and Y. Shirota, J. Am. Chem. Soc., 119, 6607 (1997).

(g) A. Ito, H. Ino, K. Tanaka, K. Kanemoto, and T. Kato, J. Org. Chem., 67, 491 (2002).

10. (a) T. Michinobu, M. Takahashi, E. Tsuchida, and H. Nishide, Chem. Mater., 11, 1969 (1999). 
(b) T. Michinobu, E. Tsuchida, and H. Nishide, Bull. Chem. Soc. Jpn., 73, 1021 (2000).

(c) M. Takahashi, T. Nakazawa, E. Tsuchida, and H. Nishide, Macromolecules, 32, 6383 (1999).

(d) H. Murata, M. Takahashi, K. Namba, N. Takahashi, and H. Nishide, J. Org. Chem., 69, 631 (2004).

(e) H. Murata, Y. Yonekuta, and H. Nishide, Org. Lett., 6, 4889 (2004).

11. J. F. Hartwig, M. Kawatsura, S. I. Hauck, K. H. Shaughnessy, and L. M. Alcazar-Roman, J. Org. Chem., 64, 5575 (1999).

12. A. Rajca, Chem. Rev., 94, 871 (1994).

13. (a) W. Yang, M. Tabata, S. Kobayashi, K. Yokota, and S. Shimizu, Polym. J., 23, 1135 (1991).

(b) Y. Kishimoto, P. Eckerle, T. Miyatake, T. Ikariya, and R. Noyori, J. Am. Chem. Soc., 116, 12131 (1994).

(c) T. Shimizu and T. Yamamoto, Chem. Commun., 515
(1999).

(d) Y. Mawatari, M. Tabata, T. Sone, K. Ito, and Y. Sadahiro, Macromolecules, 34, 3776 (2001).

14. (a) H. Tachimori and T. Masuda, J. Polym. Sci., Part A: Polym. Chem., 33, 2079 (1995).

(b) R. Nomura, S. M. Abdul Karim, H. Kajii, R. Hidayat, K. Yoshino, and T. Masuda, Macromolecules, 33, 4313 (2000).

15. R. S. Nicholson, Anal. Chem., 37, 1351 (1965).

16. The concentrated methylene chloride solution of $\mathrm{SbCl}_{5}$ was added dropwise to the dilute methylene chloride solution of the amine polymer 1 to provide a high yield upon the aminium cation radical formation. The $\mathrm{SbCl}_{6}{ }^{-}$salt of $\mathbf{1}^{+}$was isolated as a blue powder by pouring the methylene chloride solution of $\mathbf{1}^{+}$oxidized with $\mathrm{SbCl}_{5}$ into diethyl ether.

17. F. A. Neugebauer, S. Bamberger, and W. R. Groh, Chem. Ber., 108, 2406 (1975). 